\title{
EL IMPACTO DE LOS DERECHOS HUMANOS ANTE LA ESCLAVITUD DEL SIGLO XXI
}

\section{THE IMPACT OF HUMAN RIGHTS ON SLAVERY IN THE 21ST CENTURY}

\section{Candelaria del Pino Padron ${ }^{1}$}

\section{RESUMEN}

Al llevar a cabo un estudio sobre el fenómeno de la trata de seres humanos, pone de manifiesto como ésta, supone una grave vulneración de la dignidad humana, que atenta directamente contra los principios reconocidos por los derechos humanos. Es, en este sentido, donde resulta constatable la evidente relación que guarda con la histórica institución de la esclavitud.

Si bien es cierto que las instituciones de la esclavitud y la trata de seres humanos difieren en el contexto histórico, no es menos cierto que resultan absolutamente coincidentes en cuanto a la finalidad que persiguen, puesto que ambas presentan un claro indicador común con la explotación humana.

El presente trabajo, pretende realizar un análisis de la victimización y su relación con la criminalización de la delincuencia organizada.

Palabras clave: Victimología, derechos humanos, explotación humana, tráfico de personas, trata de seres humanos

\begin{abstract}
In carrying out a study on the phenomenon of trafficking in human beings, it shows how it is a grave breach of human dignity, which directly undermines the principles recognized by human rights. It is, in this sense, where the evident relationship that is with the historical institution of slavery is evident.

While it is true that the institutions of slavery and trafficking in human beings differ in the historical context, they are nevertheless absolutely coincidental as to the purpose they pursue, since they both present a clear common indicator of human exploitation .

This paper aims to analyze the victimization and its relation to the criminalization of organized crime
\end{abstract}

Keywords: Victimology, Human rights, human exploitation, trafficking in persons, trafficking in human beings

\section{INTRODUCCIÓN}

Al llevar a cabo un estudio sobre el fenómeno de la trata de seres humanos, la primera tarea que se plantea pone de manifiesto cómo ésta supone una grave vulneración de la dignidad humana,

\footnotetext{
${ }^{1}$ Letrada Colegiada del Ilustre Colegio de Abogados de Las Palmas. Doctora en Derecho por la Universidad de Las Palmas de Gran Canaria (España). Afiliação: Universidad de Las Palmas de Gran Canaria, Espanha. E-mail: Universidad de Las Palmas de Gran Canaria
} 
que atenta directamente contra los principios reconocidos por los derechos humanos. Es, en este sentido, donde es constatable en el análisis empírico que se realiza, cómo resalta la evidente relación que se da con la histórica institución de la esclavitud.

Si bien las instituciones de la esclavitud y la trata de seres humanos difieren en el contexto histórico, resultan absolutamente coincidentes en cuanto a la finalidad que persiguen, puesto que ambos presentan un claro indicador común en la explotación humana.

Así, el fenómeno de la trata de seres humanos aparece en forma de un amplio elenco de acciones humanas, que se oponen al ideario que representa la configuración de los derechos humanos.

La esclavitud ha venido entendida como una forma involuntaria de servidumbre humana. En este sentido, se suele hacer referencia a la trata de seres humanos como la moderna forma de esclavitud o la esclavitud del siglo XXI.

Una de las características fundamentales que asume el fenómeno de la esclavitud es, precisamente, el sometimiento de la persona a través del uso de la fuerza, por lo que básicamente puede definirse la esclavitud, como el estado de sometimiento en que se encuentra una persona frente a otra.

En la actualidad, la trata de seres humanos no se aleja de la idea de función socio-económica que desempeñaban los esclavos a lo largo de la historia, sobre todo en la dedicación a tareas productivas en beneficio de otra persona de forma involuntaria, expresión útil de servidumbre humana.

La trata de seres humanos, en la actualidad, se alimenta de múltiples factores culturales, sociales y económicos, tales como la pobreza, los conflictos bélicos, los desastres naturales, el analfabetismo y los movimientos migratorios, entre otros. Este tipo de factores agudizan los efectos demoledores de la trata de seres humanos y potencian los aspectos de vulnerabilidad en la población afectada.

Estas circunstancias y procesos transgresores con los derechos humanos más básicos, se proyectan sobre las personas víctimas de la trata, muchas de ellas procedentes de países inmersos en un contexto de extrema pobreza y, por tanto, vulnerables de ser captadas por las organizaciones criminales, bien de forma violenta o mediante el engaño de un futuro mejor.

La fenomenología de la trata de seres humanos se configura en un entorno de extrema pobreza y analfabetismo donde los Estados del tercer mundo o los que se encuentran inmersos en conflictos bélicos e inseguros, es donde las mafias y organizaciones delictivas son proclives a buscar y encontrar seres humanos desvalidos a los que atraer y enredar en la desesperación para hacerlos, finalmente esclavos de sí mismos, admitiendo la pérdida de libertad y autonomía personal para obtener comida o medios de subsistencia. 
Es por ello que no resulta extraño comprobar cómo en ocasiones, esa pérdida total de la libertad y autonomía personal se produce con el consentimiento de las propias víctimas. Es, precisamente en este punto, donde debemos plantearnos la validez o no de ese consentimiento. Pues la mayor parte de las veces, la víctima asume un compromiso bajo las falsas promesas de trabajo y mejores expectativas de vida, constituyendo así, un elemento diferenciador de la libre voluntad que en este caso, tipifica la forma más clara de engaño.

Así, se ha de valorar que la nueva forma de esclavitud que está asumiendo la fenomenología de la trata de seres humanos, requiere un nuevo planteamiento en materia de control y garantías sobre los derechos humanos que deben asistir, con carácter universal, a todas las personas con independencia del lugar en el que se encuentren. En este sentido, resulta destacable como la trata de seres humanos se presenta como un fenómeno transnacional que se proyecta a nivel mundial.

No son pocos los Estados que se están viendo afectados por esta nueva transgresión de los derechos naturales del hombre y que por tanto, se ven abocados a asumir ante todo, la existencia del fenómeno y el reconocimiento de las víctimas de este proceso, que acaban inmersa en las diferentes redes criminales con distintos desenlaces finales.

Es por ello, que deben articularse medidas consecuentes con este nuevo fenómeno mundial que conlleven entre otras, las mayores garantías para los derechos inherentes al ser humano.

Por lo que un primer paso en esa dirección, sería definir la trata de seres humanos como una flagrante agresión a los derechos naturales del hombre, a los derechos humanos, esto es, a los derechos fundamentales y libertades públicas que los Estados y las instituciones deben proteger, amparar, tutelar y garantizar.

Es en esa responsabilidad colectiva de los Estados que genera obligaciones de amparar y tutelar, además de garantizar los derechos naturales de la persona humana, donde la comunidad internacional se implica de manera taxativa con el objetivo de fortificar las garantías que con carácter universal, deben proteger a todo ser humano.

Precisamente por ello, se pone de manifiesto la importancia que adquiere el fenómeno de la trata, no sólo por significar una clara vulneración de los derechos humanos, sino porque se representa como una global resistencia al cumplimiento que los Estados asumen con otros Estados e instituciones internacionales.

La necesidad de establecer medidas de prevención y control ante el fenómeno de la trata de seres humanos, obliga a la comunidad internacional a adoptar una visión multidisciplinar que abre un debate acerca de su proyección en los derechos humanos, con el objetivo claro de establecer medidas de carácter social y asistencial.

El ideario de los derechos humanos, se presenta como el fundamento de las doctrinas axiológicas que posicionan al sujeto como epicentro de los atributos que le resultan inherentes a su 
propia naturaleza. En este sentido, la dignidad y los caracteres inmanentemente propios a la naturaleza del hombre, cobran todo su sentido en el fundamento de su reconocimiento.

La proyección transgresora que identifica a la trata de seres humanos, constituye una vulneración directa sobre la propia dignidad del ser humano y con ello, se instituye como evidente lesión al reconocimiento de derechos humanos universales. Es por ello, que la explotación del ser humano en cualquiera de sus manifestaciones, constituye un atentado amplio y directo a la dignidad y la libertad misma, erosionando también con ello, la integridad moral del sujeto.

La trata de seres humanos no sólo atenta contra la dignidad y la libertad, sino también se configura como una forma concreta de agresión a la integridad moral del individuo. Queda claramente definida esta afirmación cuando se constata que el sujeto, la mayor parte de las veces, se ve concernido a realizar actos denigrantes para que otros puedan alcanzar la mayor productividad económica a través de su rendimiento y, por tanto, quedar sometido a una situación que lo anula como persona.

Esa ruptura con la dignidad, la libertad y la integridad moral del individuo se ha visto a lo largo de la historia repetida en diferentes circunstancias e incluso con mayor o menor grado de aceptación social.

Así, la trata de seres humanos puede ser entendida como un fenómeno que, en cada momento histórico, transforma la asunción de las facultades que concretan las exigencias de salvaguarda que deben presidir la dignidad, la libertad y la igualdad humana.

La esclavitud viene entendida como una forma involuntaria de servidumbre humana. En este sentido, se suele hacer referencia a la trata de seres humanos como una moderna forma de esclavitud. Una de las características fundamentales que asume la esclavitud es, precisamente, el sometimiento de la persona a través del uso de la fuerza con el objetivo de explotar el rendimiento de su actividad en beneficio de otro individuo, que se configura como el titular de su persona. Por lo que, puede afirmarse que la esclavitud responde por tanto, al estado de sometimiento en que se encuentra una persona frente a otra.

El recorrido que la institución de la esclavitud ha hecho a lo largo de las distintas épocas históricas, demuestra cómo los derechos naturales del hombre fueron reconocidos paulatinamente a través del tiempo, de forma muy diferenciada.

Así, se constata en las distintas etapas históricas cómo los diferentes argumentos esclavistas que se sucedieron permitían la defensa de ciertos derechos naturales.

En este sentido, puede afirmarse que los derechos naturales reconocidos a los individuos calificados de esclavos constituían, más que valores propios de la persona, garantías seguras de que la propiedad material con fines productivos, que eran los esclavos, no se deterioraba. 
Muchos autores reconocen que la invención de la esclavitud o de cualquier práctica de sometimiento del prójimo, constituye una deshumanización total. Así en esa misma línea, autores como Marina y Valgoma afirman que "cuando apareció el hombre, el universo se amplió con invenciones maravillosas e invenciones malvadas. En ninguna de ambas ocupaciones nos hemos concedido reposo"2.

Así, en este somero recorrido podemos valorar cómo a los esclavos se les iba reconociendo el derecho a la vida, el derecho a no ser lesionados, a tener familia, entre otros, por cuanto la vulneración por parte de sus legítimos dueños de esos derechos, constituía pena punitiva onerosa para éstos.

A lo largo de la historia, se puede comprobar que ese estado de sometimiento que significaba la esclavitud, en muchas ocasiones venía protegido por la propia norma o costumbre legal.

En este sentido, las palabras que Fernández-Armesto defendiera resultan sumamente justificadas, "quienes nos creemos humanos, sentimos una confianza absoluta en nuestra identidad humana y en nuestra capacidad para reconocerla en los demás.

Aun así, el actual concepto es reciente: la mayoría de la gente, de la mayoría de sociedades a lo largo de la mayor parte de la historia, se habría quedado atónita ante una categoría tan universal.

De hecho, a muchas de esas personas les habría costado comprender la palabra 'humano' o encontrar alguna equivalencia en sus idiomas respectivos, salvo como modo de designar a los miembros de su propio grupo"3.

En este sentido, a lo largo de la historia se constata cómo se permitía que un sujeto pudiera disponer de otro sin más limitaciones que su propia voluntad.

Así, desde los tiempos más remotos, el esclavo se definía legalmente como una mercancía que el dueño podía vender, comprar, regalar o cambiar por una deuda, sin que el esclavo pudiera ejercer ningún derecho u objeción personal o legal.

\section{LA ESCLAVITUD MODERNA: LA TRATA DE SERES HUMANOS}

La perspectiva comercial que adquirió en las etapas históricas últimas, la antigua institución de la esclavitud ha ido dando un dramático giro, constituyendo la actual trata de seres humanos.

Aunque no cabe identificar plenamente una institución con otra, la virtual vulneración de los derechos humanos actuales es totalmente comparable con la nula atención a los derechos naturales que se daba en la esclavitud antigua.

\footnotetext{
${ }^{2}$ MARINA, J.A. y VALGOMA, M., La lucha por la dignidad, Anagrama, Madrid, 2005, p. 18.

${ }^{3}$ FERNÁNDEZ-ARMESTO, F., Breve historia de la humanidad, Ediciones B, Barcelona, 2005, p. 13.
} 
Un modo de esclavitud moderno, aunque no el único, es la trata de seres humanos. La proyección transgresora que adquiere la trata de seres humanos constituye una vulneración de lesa humanidad por cuanto, en ese sentido, negar la dignidad de un solo ser humano hasta el punto de comerciar con su vida e inquietudes vitales constituye, de facto, una lesión al reconocimiento de derechos humanos universales.

La trata de seres humanos en la actualidad, se incardina en ambientes sociales económica y culturalmente quebrados. Las poblaciones más vulnerables son las que están desamparadas por razones de diversa índole, como puede ser la guerra, la hambruna y todo lo que conlleva las situaciones de precariedad. En este sentido, esta situación es proyectada en las personas secuestradas o cautivas, procedentes de países en un contexto de extrema pobreza y, por tanto, vulnerables para ser captadas, bien de forma violenta o mediante el engaño de un futuro mejor. Por lo que resulta destacable señalar que en ocasiones esa situación determinante de la trata de seres humanos es consentida por las víctimas, pues éstas aceptan ser sometidas basándose en falsas promesas de trabajo y mejores expectativas de vida, constituyendo así, un elemento que tipifica la forma más clara de engaño.

La trata de seres humanos se presenta en la actualidad, como un fenómeno de gran repercusión que está afectando a muchos Estados. La base de esa preocupación parece recaer sobre la manifiesta vulneración de los derechos naturales del individuo. Esto representa un ataque directo a los derechos humanos, a los derechos fundamentales y libertades públicas que los Estados y las instituciones deben amparar y tutelar.

La responsabilidad social se amplía cuando la trata de seres humanos adquiere un cariz internacional. En este sentido, alcanza esa categoría geopolítica por cuanto existen voluntades diversas implicadas en la estrategia de trata de seres humanos a ese nivel. Precisamente por ello, se pone de manifiesto la importancia que adquiere este fenómeno, no sólo por la vulneración que implica sobre los derechos fundamentales de la persona, sino también porque representa una global resistencia al cumplimiento exigente de la obligación que los Estados asumen con otros Estados e instituciones internacionales.

La necesidad de establecer medidas de prevención y control en la trata de seres humanos, obliga adoptar una visión multidisciplinar que abre un debate sobre su proyección en los derechos humanos, con el objetivo claro de establecer medidas de carácter social y asistencial.

La trata de seres humanos supone una violación de derechos humanos que se manifiesta en la actualidad como un grave problema de carácter internacional, ya que viene concebida como el secuestro, el traslado o retención de seres humanos a través de la amenaza y el uso de violencia. La trata de seres humanos supone una vulneración clara de la dignidad y la libertad del ser humano. Derechos que, de entrada, se suponen universales y quedan cercenados con este fenómeno. 
Los derechos subjetivos del individuo sufren un perjuicio irreparable, por cuanto se atenta contra el propio espíritu de libertad que posee innatamente la persona, su dignidad queda escindida en pro de la voluntad de su virtual propietario. Por lo que no sólo se lesiona internamente el espíritu mismo de la dignidad del sujeto, sino que estas reiteradas vulneraciones de los derechos naturales del hombre suponen una considerable depreciación de la persona, en su acepción biológica natural. Pues la proyección física del individuo abarca, también, un plano espiritual tocante a los derechos subjetivos, que Ferrajoli definía perfectamente cuando afirmaba que "los derechos humanos son derechos subjetivos, son expectativas formadas en todas las personas con relación a la acción u omisión de los Estados, las empresas, los poderes fácticos y del resto de las personas respecto a ciertos bienes primarios"4.

Estos derechos, vulnerados de forma lacerante en la trata de seres humanos, por su indudable valor para toda la humanidad deben ser específicamente tutelados y protegidos por el poder vigente. Pues esa innegable valía deriva de que pertenecen al ser humano como derechos inmanentemente propios e inherentes a su propia naturaleza y no como mera mercancía transferible con el objetivo de explotación. En este sentido, Truyol y Serra afirma que "existen derechos fundamentales que el hombre posee por el hecho de ser hombre, por su propia naturaleza y dignidad; derechos que le son inherentes, y que, lejos de nacer de una concesión de la sociedad política, han de ser por ésta consagrados y garantizados"

Toda relación de esclavitud se basa en el principio de propiedad. En este punto, son las redes criminales internacionales, a través de la explotación, las que se lucran por los servicios que prestan las personas esclavizadas. En esta línea, Rosario Serra defiende que "el tipo de explotación del ser humano a la que puede verse sometida una víctima de la trata constituye, sin duda alguna, un atentado a su dignidad y libertad" derechos humanos en el caso que nos ocupa, se ahonda sobre las causas que desembocan en este fenómeno que está adquiriendo notoria relevancia en la actualidad. Autores como Esteban Pérez entienden que, desde la perspectiva de nuestro derecho positivo, podemos conceptualizar el delito de la trata de seres humanos como una forma concreta de agresión a la integridad moral del individuo. El sujeto se ve concernido a realizar actos denigrantes para que otros puedan alcanzar la mayor productividad económica a través de su rendimiento, y por tanto, queda sometido a una situación que "lo anula como persona"7.

\footnotetext{
${ }^{4}$ FERRAJOLI, L., Sobre los derechos fundamentales, Trotta, Madrid, 2001, p. 30.

${ }^{5}$ TRUYOL y SERRA, A., Los Derechos Humanos, Tecnos, Madrid, 2000, p. 11.

${ }^{6}$ SERRA CRISTOBAL, R. y LLORIA GARCÍA, P., La trata sexual de mujeres. De la represión del delito a la tutela de la víctima, Ministerio de Justicia de España, Madrid, 2007, p. 30.

${ }^{7}$ PÉREZ ALONSO, E. J., Tráfico de personas e inmigración clandestina (un estudio sociológico, internacional y jurídico-penal), Tirant lo Blanch, Valencia, 2008, pp. 177, 181, 332.
} 
Partiendo de la anterior consideración, entiende el Tribunal Constitucional que la dignidad de la persona es "una cualidad ínsita a la misma, que por lo tanto corresponde a todo ser humano con independencia de sus concretas características particulares, y a la que se oponen frontal y radicalmente los comportamientos prohibidos en el artículo 15 de nuestra Constitución, bien porque cosifican al individuo, rebajándolo a un nivel material o animal, bien porque lo mediatizan o instrumentalizan, olvidándose de que la persona es un fin en sí mismo"8.

La importancia que asumen, por tanto, los derechos humanos como garantía de tutela en la persona, se ve entendida en autores como Galván cuando defiende que "el ejercicio de los derechos humanos permite que el ser humano dé vigencia a sus derechos de libertad, igualdad, salud y educación, entre otros, acorde siempre al principio de dignidad de la persona. Para lograr su realización es necesario que el Estado determine los mecanismos que garanticen su respeto y protección" $"$.

En un primer intento de aproximación sobre el fenómeno de la trata de seres humanos, se realizará un análisis detenido sobre una realidad espantosa, que Ignacio Ramonet describe con mucho acierto, apuntando que "dos siglos después de la abolición de la esclavitud, regresa una práctica abominable: la trata de personas" ${ }^{\prime 10}$.

La Organización Internacional del Trabajo (OIT.), a través de múltiples informes, estima que son millones de personas en el mundo las que se ven sometidas, por redes ligadas a la criminalidad internacional, a la explotación por la fuerza, en trabajos contra su voluntad y en condiciones inhumanas. Tratándose de mujeres, la mayoría son víctimas de explotación sexual, mientras muchas otras son específicamente explotadas en el servicio doméstico. También se da el caso de personas jóvenes y en buen estado de salud que, bajo diversos engaños, son privadas de su libertad y de su derecho a un desarrollo de su personalidad, perdiendo en el camino su identidad, derechos, dignidad.

\section{UNA MIRADA DESDE LA ÓPTICA DE LAS VÍCTIMAS INVISIBLES}

No cabe duda que una práctica en la que un ser humano usa de otro, de manera abusiva y sin consentimiento válido, lesionando el espíritu natural de la víctima y forzándola a cambiar su propia idiosincrasia de vida, significa violentar los derechos innatos del ser humano en todos sus

\footnotetext{
${ }^{8}$ PASCUAL LAGUNAS, E., Configuración jurídica de la dignidad humana en la jurisprudencia del Tribunal Constitucional, Bosch, Barcelona, 2009, p. 73. En este sentido, se hace valer el texto de la Sentencia del Tribunal Constitucional, se extrae de la Sentencia del Tribunal Constitucional número 181/2004 de 2 de Noviembre de 2004, Fundamento Jurídico 13.

${ }^{9}$ GALVÁN TELLO, M. C., "La educación en Derechos Humanos en la enseñanza del Derecho: un desafío", en Los derechos humanos en la educación jurídica, Plaza y Valdés, México, 2012, p. 94.

${ }^{10}$ RAMONET, I., "Esclavos en Europa", en Le Monde Diplomatique, Número 189, Valencia, 2011, pp. 44-45.
} 
parámetros. En ese sentido, puede entenderse que los derechos de las víctimas de la trata se transgreden al menos en tres momentos.

En primer lugar, por parte de los gobiernos, que en no pocas ocasiones consienten, e incluso fomentan, todo tipo de acciones discriminatorias contra los sujetos especialmente vulnerables, como son las mujeres, niños, inmigrantes, o cualquier otro sujeto en riesgo de exclusión por razones económicas o sociales. En segundo lugar, sin lugar a dudas, son los tratantes los que atentan gravemente contra los derechos humanos de los sujetos a los que someten, despojándolos de su dignidad a través de los medios más aberrantes y atroces. Por último, desde las instituciones internacionales, en cuanto a su obligación en la persecución y castigo de las redes criminales de ámbito transnacional, que vulneran de forma sistemática los derechos humanos de sus víctimas.

La Trata de seres humanos viola los derechos humanos reconocidos, que se encuentran plasmados y positivizados en una serie de instrumentos internacionales de protección, tutela y garantía. Estos instrumentos establecen derechos humanos que se aplican a todas las personas: hombres, mujeres, niños; en general a toda persona víctimas de la Trata. Los derechos humanos que se presentan en el contexto de la Trata de Personas son el derecho a la vida, a la salud, a la libertad, a la seguridad jurídica y a la autonomía, entre otros, todos ellos derivados de la dignidad innata del ser humano.

Como hemos defendido con anterioridad, la trata de seres humanos tiene históricamente su génesis en la esclavitud, y es a través del paso del tiempo cuando ha ido cristalizando en la actualidad en el fenómeno que Bales señala como "la nueva esclavitud" ". En este mismo sentido, plantea Tessier que la actual trata de seres humanos se puede definir como "la moderna trata de esclavos del siglo XXI"12 o "La nueva esclavitud del siglo XXI"13.

En la actualidad, se puede observar cómo a través de diversas formas de explotación humana se vulneran, de manera flagrante los derechos humanos, derechos que deben ostentar las personas con independencia de circunstancias ajenas a la propia esencia humana. Así, para el profesor Pérez Luño, los derechos que se vulneran en la trata de seres humanos vienen entendidos como "un conjunto de facultades e instituciones que, en cada momento histórico, concretan las exigencias de la dignidad, la libertad y la igualdad humana. Estas facultades son reconocidas positivamente"14. Esas facultades a las que se hace referencia, y que se le atribuyen al ser humano como facultades

\footnotetext{
${ }^{11}$ BALES, K., La nueva esclavitud en la economía global (traducción de Borrajo Castanedo), Siglo XXI Editores, Madrid, 2000, p. 7.

12 TESSIER, K., The New Slave Trade: The International Crisis of Immigrant Smuggling, Volumen XIII, Indiana Journal of Global Legal Studies, Indiana, 1995, p. 261.

${ }^{13}$ PÉREZ ALONSO, E. J., "La Trata de seres humanos en el Derecho Penal Español”, en AA.VV., C. Villacampa Estiarte (coord.) La Delincuencia Organizada: Un reto a la Política Criminal Actual, Aranzadi, Navarra, 2013, p. 94.

${ }^{14}$ PÉREZ LUÑO, A. E., Los Derechos Fundamentales, Tecnos, Madrid, 1984, p. 46.
} 
inherentes a su condición, para el profesor Ara Pinilla vienen entendidas como "un reflejo en el propio consenso social alcanzado a partir de la realización de las exigencias de liberación de los condicionamientos que puedan sufrir la formación y la expresión de la voluntad de los individuos" $" 15$.

En el caso de la trata, no cabe duda de que esos "derechos humanos" constituyen un valor persuasivo, muchas veces utilizado para convencer y no para describir, y del que frecuentemente se abusa" ${ }^{\prime \prime}$. Puesto que en el caso de la trata de seres humanos, el valor que asumen los derechos humanos queda totalmente desvirtuado. Representándose la trata de seres humanos como una nueva forma de esclavitud en la sociedad contemporánea, resulta necesario atender a su contextualización y a la proyección que en la actualidad asume. La profesora Gemma Nicolás plantea que "las preocupaciones modernas respecto de la prostitución y la trata de mujeres tienen su precedente histórico en las pretéritas campañas contra la trata de blancas a finales del siglo XIX"17.

Hasta finales del siglo XX, el tráfico de personas era conocido con el término "trata de blancas", por su implicación con el comercio de mujeres blancas europeas y americanas, con las que se comercializaba para prostituirlas en África, Asia y el Este de Europa.

A través de la evolución del tráfico de seres humanos se produce un giro en su denominación, de manera que el tráfico de personas evoluciona hacia la comercialización de hombres, mujeres, niños, niñas y adolescentes.

Hasta el momento en que se aprueba el Protocolo de Palermo, todas las referencias normativas anteriores trataban el fenómeno desde el concepto de "trata de blancas". En referencia a la conceptualización de la trata de blancas, la profesora Sonia García, desde una perspectiva histórica, refiere que el término "trata de blancas" fue utilizado por primera vez en la Conferencia de Paris de 1902, dirigida a la creación de un instrumento internacional para la supresión del tráfico de esclavas blancas. Aunque inicialmente la única finalidad fue diferenciar esta conducta del comercio de esclavos negros, lo cierto es que dichas prácticas incluían mujeres de todas las razas y por ello, en el año 1921, se recomendó el abandono de este concepto equívoco por el de tráfico de mujeres y niñas." 18

Defendiendo que se trata de "un problema antiguo pero que sigue siendo de actualidad"19, desde ésta perspectiva y en la misma línea, otros autores señalan la trata de seres humanos como un

\footnotetext{
15 ARA PINILLA, I., Las transformaciones de los derechos humanos, Tecnos, Madrid, 1994, p. 63.

${ }^{16}$ Ibídem, p. 16.

${ }^{17}$ NICOLÁS LAZO, G., "Migraciones femeninas y trabajo sexual: Concepto de trabajo precario versus tráfico de mujeres", AA.VV., R. Bergalli (coord.) Flujos migratorios y su (des)control. Puntos de vista pluridisciplinarios, Anthropos, Barcelona, 2006, pp. 229-260.

18 GARCÍA VÁZQUEZ, S., "La lucha contra la trata de seres humanos a nivel internacional, comunitario y nacional", en AA.VV., M. C. Vidal Fueyo (coord.) La Trata de Seres Humanos, Centro de Estudios Políticos y Constitucionales, Madrid, 2012, p. 18.

${ }^{19}$ FINLEY, M. I., Esclavitud antigua e ideología moderna, Barcelona, Crítica, 1982, p. 20.
} 
“problema viejo con un nombre nuevo" ${ }^{20}$. Así, en la misma línea, Bales afirma con respecto a la esclavitud, que es un fenómeno que "nunca ha desaparecido, sino que ha cambiado de forma" ${ }^{21}$. La repercusión y el alcance que se proyecta a través de este fenómeno es la reafirmación de la convicción de que la trata de seres humanos implica la nueva fórmula de esclavitud que se practica en nuestro tiempo, ejercida desde distintas fórmulas de explotación del ser humano, en detrimento y vulneración de sus más elementales derechos.

Tradicionalmente, la trata de seres humanos se ha vinculado a la inmigración que se produce desde zonas deprimidas y más desfavorecidas económicamente. Cepeda reconoce que "las causas principales de la trata son muy complejas y muy a menudo están interrelacionadas entre sí. Pero lo que sí está claro es que uno de los factores más importantes de donde viene esta nueva esclavitud, se encuentra en la mundialización, donde se ha desarrollado en un mundo muy desigualitario, bajo unas declaraciones de poder muy asimétricas, propiciando un sistema de intercambios desiguales entre países y acentuando la dominación de clase y de género ya existentes"22.

\section{CONCEPTUALIZACIÓN DE LA FENOMENOLOGÍA}

Dar un concepto claro y certero que defina la Trata de seres humanos es sumamente sencillo, lo difícil es concretar en qué punto de la historia los seres humanos han dejado de ser fuente de poder para sus congéneres, o si alguna vez han dejado de serlo.

En este sentido, podemos constatar lo que afirmara Todorov respecto del goce del poder; "Si el sufrimiento del otro es la mejor prueba de mi poder, no es la única: su felicidad lo es también, aunque lo sea en un grado menor"23.

Los seres humanos nos lesionamos y hacemos del otro una fuente de poder o riqueza, sin tener en cuenta que la capacidad deshumanizadora se adquiere y revela trascendente en la víctima, cuando esta ejerce esa misma actitud hacia terceros.

La primera cuestión que debemos abordar, en cuanto a la conceptualización de la trata de seres humanos, es la utilización del término trata, refiriéndonos a su acepción anglosajona "trafficking in persons". Esta acepción es utilizada por la Convención de Naciones Unidas contra el crimen Organizado Transnacional ${ }^{24}$. En este sentido, será el Protocolo de Palermo el que proporcione un concepto normativo de trata de seres humanos.

\footnotetext{
${ }^{20}$ OIM, Trata de Personas: Aspectos Básicos, Cim/Oea, México 2006, p. 9.

${ }^{21}$ BALES, K., La nueva esclavitud en la economía global, cit., p. 13.

${ }^{22}$ PÉREZ CEPEDA A. I., Globalización, tráfico internacional ilícito de personas y derecho penal, Comares, Granada, 2004, p. 1.

${ }^{23}$ TODOROV, T., 1993, Frente al límite, Siglo XXI editores, México, 1993, p. 208.

${ }^{24}$ Protocolo para Prevenir, Reprimir y Sancionar la Trata de Personas, especialmente de mujeres y niños. Palermo, 2000. Ratificado por España el 11 de noviembre 2003, en vigor el 25 de diciembre de 2003.
} 
Por otro lado, cuando hacemos referencia al término tráfico ilícito de inmigrantes, se parte de la acepción anglosajona de "smugling of migrants"25. La confusión terminológica se produce precisamente por asumir la traducción literal en español del término tráfico de personas, que en la versión inglesa sería "trafficking in persons".

Para superar esta falta de precisión que se produce en la semántica, la conceptualización de ambos términos viene de la mano de Naciones Unidas. En el caso del tráfico ilegal de seres humanos, se entiende por trata el procedimiento para obtener, directa o indirectamente, un beneficio económico de la entrada ilegal de una persona en un país del que no es nacional ni residente permanente.

Es así como se configura el nuevo modelo de tráfico de seres humanos, cuya proyección no tiene distinción ante cualquier género, raza o etnia, convirtiéndose en un fenómeno de alcance transnacional. Por tanto, la trata de personas o de seres humanos constituye en la actualidad, una realidad que asume un entramado sumamente complejo.

La Convención sobre la Esclavitud de 1926, nos indica una clara definición de lo que era la antigua esclavitud y que actualmente puede ser asimilada por la Trata de seres humanos. Así, la definición de la esclavitud como "el estado o condición de una persona sobre la cual se ejercen algunos o todos los poderes relacionados con el derecho de propiedad. El comercio de esclavos incluye todos los actos involucrados en la captura, adquisición o la disposición de una persona con el fin de reducirla a la esclavitud; la adquisición de un esclavo con miras a venderlo o intercambiarlo; disposición para la venta o intercambio de un esclavo adquirido con miras a venderlo o intercambiarlo; comercio y transporte de esclavos" ${ }^{\prime 26}$.

Con carácter general, la doctrina entiende que el concepto normativo de trata, responde al contenido del artículo 3 del Protocolo para Prevenir Reprimir y Sancionar la Trata de Personas, Especialmente de Mujeres y niños ${ }^{27}$, que complementa la Convención de Naciones Unidas contra la Delincuencia Organizada Transnacional ${ }^{28}$ y así viene entendido cuando defiende que:

\footnotetext{
${ }^{25}$ Es frecuente que se confundan ambos términos por la coincidencia del vocablo inglés "trafficking" con el castellano "tráfico" lo que lleva a posibles interpretaciones erróneas respecto a los términos tráfico de migrantes y trata de seres humanos. La traducción castellana de "smuggling" se corresponde con contrabando, en las fronteras de los países hispanos se utiliza vulgarmente el término tráfico para designar la actividad de favorecer la entrada ilegal de migrantes en el país. Por otro lado, en lo que se refiere a la trata, el vocablo inglés para denominarla se corresponde con "trafficking" que es una acepción empleada habitualmente para referirse al comercio internacional de seres humanos con fines de explotación económica. Dicho esto, es normal que habitualmente se confundan los conceptos de trata y tráfico, en cualquier caso la correspondencia correcta sería denominar a la trata como "trafficking in persons" y al contrabando o entrada ilegal de migrantes como "smuggling of migrants",

${ }^{26}$ Convención sobre la Esclavitud (1926).

${ }^{27}$ Protocolo para Prevenir Reprimir y Sancionar la Trata de Personas, Especialmente de Mujeres y niños. Palermo, 2000. Ratificado por España el 11 de noviembre 2003 que entró en vigor el 25 de diciembre de 2003, que contiene en su artículo 3 la definición básica de la trata de seres humanos.

28 Asamblea General de la Organización de Naciones Unidas. Convención de Naciones Unidas Contra la Delincuencia Organizada Transnacional. Nueva York, 15 de noviembre del año 2.000
} 
“a) Por trata de personas se entenderá la captación, el transporte el traslado la acogida o recepciones de personas recurriendo a la amenaza o uso de la fuerza u otra formas de coacción, al rapto, al fraude, al engaño, al abuso de poder o de una situación de vulnerabilidad o a la concesión o recepción o pagos o beneficios para obtener el consentimiento de una persona que tenga autoridad sobre otra, con fines de explotación. Esta explotación incluirá, como mínimo, la explotación de la prostitución ajena u otras formas de explotación sexual, los trabajos o servicios forzados, la esclavitud o prácticas análogas a la esclavitud, la servidumbre o la extracción de órganos.

b) El consentimiento dado por la víctima de la trata de personas a toda forma de explotación intencional descrita en el apartado a) del presente artículo no se tendrá en cuenta cuando se haya recurrido a cualquiera de los medios enunciados en dicho apartado.

c) La captación, el transporte, la acogida o la recepción de un niño con fines de explotación se considera "trata de personas" incluso cuando no se recurra a ninguno de los medios enunciados en el apartado a) del presente artículo;

d) Por "niño" se entenderá toda persona menor de 18 años." 29

Para la profesora Carolina Villacampa, la aprobación del Protocolo de Palermo “constituyó un hito en la lucha contra la trata de personas a nivel internacional, pues constituye el primer documento emitido por Naciones Unidas en que el concepto de trata deja de ser identificado únicamente con el concepto de trata de blancas, como hasta el momento lo había sido, incorporándose al mismo una serie de conductas realizadas con determinados medios y con invariable finalidad de explotar a la víctima con independencia de su nacionalidad." ${ }^{30}$

Aunque lo cierto es que en éste Protocolo, conocido como Protocolo de Palermo, se aborda de forma pionera el fenómeno desde el término de "trata de personas".

Con la nueva configuración que realiza el artículo 3, se proporciona un impulso internacional en cuanto a la lucha contra la trata de personas se refiere, puesto que se contemplan una serie de medios por los que se alcanza la finalidad de explotación económica del ser humanos como una vulneración de los derechos humanos, sin entrar a considerar su país de su origen.

Desde un punto de vista doctrinal, es el profesor Muñoz-Conde quien nos brinda un concepto sobre trata de seres humanos cuando defiende que ésta constituye "una actividad criminal, universal, que se caracteriza por el abuso de una situación de superioridad y de la necesidad económica que padecen personas cuya pobreza genera el tráfico y el transporte a otros países

\footnotetext{
${ }^{29}$ Protocolo para Prevenir Reprimir y Sancionar la Trata de Personas, Especialmente de Mujeres y niños Ratificado por España el 11-12-2033 que entró en vigor el 25 de diciembre de 2003 que contiene en su artículo 3 la definición básica de la trata de seres humanos.

${ }^{30}$ VILLACAMPA ESTIARTE, C., El delito de trata de seres humanos. Una incriminación dictada desde el derecho internacional. Aranzadi, Pamplona, 2011, p. 34.
} 
distintos al de origen, para aprovecharse de ellas como mano de obra barata, en condiciones muy parecidas a la "esclavitud"; para explotarlas sexualmente o extraerles sus órganos corporales" 31 .

Desde ésta definición, el autor nos adelanta las principales características expositoras de la trata, tales como el de la transnacionalidad, su relación con el crimen organizado, el perfil de la víctima a través de las circunstancias que determinan su modo de vida y, sobre todo, la subyugación de la persona a través de las distintas formas de explotación a la que se la somete.

\section{TRATA DE SERES HUMANOS VERSUS TRÁFICO ILEGAL DE PERSONAS}

Como hemos venido defendiendo hasta el momento, la denominación del fenómeno de la trata y el fenómeno del tráfico, suelen verse asumidas en el lenguaje ordinario de igual forma por su referencia semántica.

Corresponde precisar, por tanto, las diferencias que existen entre ambos fenómenos, puesto que cuando hablamos sobre la conceptualización de trata de seres humanos no resulta difícil que haya personas que no hagan distinciones entre la trata de seres humanos con fines de explotación sexual, tráfico ilegal o prostitución.

No en pocas ocasiones, los conceptos de trata de seres humanos y tráfico de migrantes o tráfico ilegal, han sido usados como sinónimos. Sin embargo, hacen referencia a conceptos disímiles, precisamente por ello, de ahí surge la necesidad de aclarar las diferencias existentes en ambos fenómenos. En este orden de cosas, una definición clara sobre el tráfico ilegal de personas nos viene dada por el Protocolo de la Organización de Naciones Unidas contra el tráfico ilícito de migrantes por tierra, mar y aire, donde enfatiza el valor de la libertad y dignidad del ser humano con carácter universal.

Así viene recogido en el texto normativo cuando expone que "contra el tráfíco ilícito de migrantes por tierra, mar y aire, se define en el artículo 3, en su apartado a), el tráfico de migrantes como "la facilitación dispuesta para obtener, directa o indirectamente, un beneficio económico o material de otro tipo, de la entrada ilegal de una persona en un Estado parte, del cual no es nacional o residente permanente" ${ }^{, 32}$.

A través de esta conceptualización, podemos comprobar que la finalidad última que persigue el tráfico ilegal de inmigrantes, no es el ánimo de lucro a través de ninguna forma de explotación, sino la que se transgrede de esta forma es la legislación migratoria. En este sentido, la inmigración, sobre todo la inmigración ilegal, supone un caldo de cultivo para aumentar los

\footnotetext{
${ }^{31}$ MUÑOZ CONDE, F., Derecho Penal. Parte Especial, Tirant lo Blanch, Valencia, España, 2010, p. 356.

${ }^{32}$ Protocolo Contra el Tráfico Ilícito de Migrantes por Tierra, Mar y Aire, que Complementa la Convención de las Naciones Unidas Contra la Delincuencia Organizada Transnacional. Resolución 55/25 de la Asamblea General, de 15 de noviembre de 2000.
} 
indicadores criminógenos, en el perfil delictual que hace referencia a las organizaciones que mercadean con seres humanos.

Ahora bien, a pesar de que ambos términos operan sobre el mismo arsenal conceptual, debemos señalar las diferencias notorias que existen entre ambos conceptos. Ello, qué duda cabe, nos permitirá obtener un resultado más comprensible sobre el fenómeno al que hacemos referencia.

Un intento de aproximación sobre la delimitación conceptual del fenómeno de la trata de personas y del tráfico ilícito de inmigrantes, nos hace comprobar que ambos fenómenos deben ser entendidos de manera separada. Esta exigencia responde a las diferencias existentes entre ambas, y sin duda alguna, obligan a observar los rasgos diferenciadores que, no en pocas ocasiones, resultan bastantes difusos.

La profesora Sonia García defiende, desde esta perspectiva, que ambos términos "siempre se han separado por una ambigua línea sombreada, la trata de personas y el tráfico ilícito de migrantes son delitos distintos pero representan problemas en parte coincidentes $y$, es por ello, que sus definiciones jurídicas contienen elementos comunes. No obstante, hay que delimitar el concepto de tráfico de personas, distinguiendo entre trata de personas y tráfico ilícito de personas" ${ }^{33}$. En esta línea apunta Sonia García, especificando que entre el tráfico ilícito de migrantes y la trata de personas hay tres diferencias radicales que permiten individualizarlos, así como las características que la definen; encontramos el consentimiento, la explotación, la transnacionalidad, entre otras.

\section{El consentimiento}

En el caso del tráfico ilícito, aunque suela realizarse en condiciones peligrosas o degradantes, los inmigrantes prestan su consentimiento; mientras que las víctimas de trata, por el contrario, nunca han consentido o, si lo hicieron inicialmente, ese consentimiento ha perdido todo su valor por la coacción, el engaño o el abuso posterior por parte de los traficantes.

El consentimiento constituye el principio básico de cualquier relación o compromiso de naturaleza contractual. Por ello, la manifestación de la voluntad de la persona, como rasgo diferenciador, supone una clara evidencia para diferenciar ambas situaciones.

Por un lado, y tratándose del tráfico ilegal de personas, hay que destacar como elemento diferenciador la existencia de manifestación de la voluntad de los sujetos. En cambio, en el caso de la trata, en ninguno de los casos existe una autonomía de la voluntad a la hora del consentimiento, puesto que la autonomía del individuo queda reducida mediante la coacción, el miedo, el engaño o la extorsión.

\footnotetext{
${ }^{33}$ GARCÍA VÁZQUEZ, S., "Inmigración ilegal y Trata de personas en la Unión Europea: La desprotección de las víctimas", en Revista de Derecho Constitucional europeo, Año 5, Número 10, julio-diciembre, 2008, p. 3.
} 
Como aspecto más característico del tráfico ilegal de migrantes, señalaremos que es la persona migrante la que se pone en contacto con los traficantes "voluntariamente" para que las trasladen a los países del denominado "primer mundo". En este contexto, el traficante de migrantes ilegales no necesita articular ningún tipo de estrategia para la captación, además de que la relación con la persona transportada acaba una vez que ésta cruza la frontera del país de destino.

\section{La explotación}

El tráfico ilícito termina con la llegada de los inmigrantes a su destino, en tanto que la trata implica la explotación persistente de las víctimas a posteriori. Este dato explica perfectamente por qué las víctimas de la trata suelen resultar gravemente afectadas y tener más necesidad de protección que los inmigrantes clandestinos.

Una diferenciación básica entre ambos conceptos resulta del objetivo final: en el caso que nos ocupa, el tráfico ilegal, una vez que los sujetos llegan al destino, la posible conexión con el transportador finaliza en ese momento. Por el contrario, cuando de trata de seres humanos se refiere, es en el mismo instante en que llega a su destino, cuando comienza el calvario de la persona víctima de dicho fenómeno.

\section{La transnacionalidad}

El tráfico ilícito es siempre transnacional, mientras que la trata puede no serlo. Ésta puede tener lugar independientemente de si las víctimas son trasladadas a otro Estado o sólo son desplazadas de un lugar a otro dentro del mismo Estado. ${ }^{34}$

Como hemos venido defendiendo, en todo caso el tráfico ilegal de seres humanos responde siempre a la idea de fenómeno transnacional. Sin embargo, en la trata de seres humanos, resulta difícil obviar que todos los países están expuestos a que se pueda producir tal situación en sus propias delimitaciones territoriales. Por ello, cuando se trata se refiere, ésta no puede entenderse como un fenómeno transnacional, sino que también puede producirse a nivel nacional, en un país en concreto. Nos referimos a los casos de trata interna. Tal es así, que el traslado de la víctima hacia otro lugar es una fase más del proceso de trata. Es decir, que la fase de transporte no se configura como elemento necesario para la plena ejecución de la trata de personas.

\footnotetext{
${ }^{34}$ FERNÁNDEZ OLALLA, P. "Una aproximación práctica a la lucha contra la trata de seres humanos en España", en AA.VV., M. C. Vidal Fueyo (coord.) La Trata de Seres Humanos, Centro de Estudios Políticos y Constitucionales, Madrid, 2012, p. 22.
} 


\section{LA CRIMINALIDAD ORGANIZADA COMO PRESUPUESTO NECESARIO}

La definición que nos aporta las Naciones Unidas, a través de la Convención De Las Naciones Unidas Contra la Delincuencia Organizada Transnacional y sus Protocolos, concreta la red criminal como un "Grupo estructurado de tres o más personas existente por un periodo de tiempo y que tenga por fin la comisión de un delito transnacional grave, mediante una acción concertada recurriendo a la intimidación, la violencia, la corrupción o a otros medios para obtener, directa o indirectamente, un beneficio económico u otro beneficio de orden material".

En concordancia, nuestro ordenamiento interno, en la Ley de Enjuiciamiento Criminal en su artículo 282 bis $^{35}$, define la delincuencia organizada como una "asociación de tres o más personas para realizar, de forma permanente y reiterada, conductas que tengan como fin alguno de los siguientes delitos: secuestro de personas, prostitución, contra el patrimonio, contra los derechos de los trabajadores,...". A tal respecto, se puede observar que nuestro derecho positivo considera las organizaciones criminales que se dedican al tráfico de seres humanos como delincuencia organizada.

En cuanto a la estructura de las organizaciones criminales, la profesora Sonia García defiende que su modo de actuar responde "como una empresa jerarquizada, usando medios violentos, persuasivos métodos de corrupción policial y judicial, y con un alto grado de profesionalización"36. Destaca, de tal forma, el gran nivel de organización y estructura que presentan estas mafias criminales.

Siguiendo la misma línea, Isabel Sánchez expone que uno de los principales rasgos que hay que destacar en el grupo criminal es "el alto grado de profesionalización de sus miembros. La presencia de una estructura, integrada por un cierto número de personas y con voluntad de tener una permanencia en el tiempo más allá de lo circunstancial, es característica en él"37.

Estas organizaciones delictivas presentan, como hemos apuntado, principalmente una estructura piramidal o jerarquizada ${ }^{38}$, con unos roles perfectamente delimitados. En el vértice se sitúan los miembros que están alejados de la ejecución material de los delitos, no obstante, son aquellos que toman las decisiones y diseñan las estrategias del grupo. Así defiende la profesora Sánchez, que estas organizaciones se auxilian de distintos profesionales como abogados,

\footnotetext{
${ }^{35}$ Ley de Enjuiciamiento Criminal, aprobada por Real Decreto de 14 de septiembre de 1882, Boletín Oficial del Estado, Número 260, de 17 de septiembre de 1882.

${ }^{36}$ GARCÍA VÁZQUEZ, S., "La lucha contra la trata de seres humanos a nivel internacional, comunitario y nacional", cit., p. 23.

37 SÁNCHEZ GARCÍA DE PAZ, M. I., La criminalidad organizada: aspectos penales, procesales, administrativos y policiales, Dykinson, Madrid, 2009, p. 57.

${ }^{38}$ Ibídem, p. 57.
} 
economistas, para configurarse como verdaderas empresas criminales, con un alto grado de imbricación en la economía legal y la Administración pública, en sus diferentes niveles ${ }^{39}$.

\section{CONCLUSIONES}

Al llevar a cabo un estudio sobre el fenómeno de la trata de seres humanos, la primera tarea que se plantea pone de manifiesto cómo ésta supone una grave vulneración de la dignidad humana, que atenta directamente contra los principios reconocidos por los derechos humanos. Es, en este sentido, donde es constatable en el análisis empírico que se realiza, cómo resalta la evidente relación que se da con la histórica institución de la esclavitud.

Si bien las instituciones de la esclavitud y la trata de seres humanos difieren en el contexto histórico, resultan absolutamente coincidentes en cuanto a la finalidad que persiguen, puesto que ambos presentan un claro indicador común en la explotación humana.

La fenomenología de la trata de seres humanos se configura en un entorno de extrema pobreza y analfabetismo donde los Estados del tercer mundo o los que se encuentran inmersos en conflictos bélicos e inseguros, es donde las mafias y organizaciones delictivas son proclives a buscar y encontrar seres humanos desvalidos a los que atraer y enredar en la desesperación para hacerlos, finalmente, esclavos de sí mismos, admitiendo la pérdida de libertad y autonomía personal para obtener comida o medios de subsistencia.

Es por ello, que no resulta extraño comprobar cómo en ocasiones, esa pérdida total de la libertad y autonomía personal se produce con el consentimiento de las propias víctimas. Es precisamente, en este punto, donde debemos plantearnos la validez o no de ese consentimiento. Pues la mayor parte de las veces, la víctima asume un compromiso bajo las falsas promesas de trabajo y mejores expectativas de vida, constituyendo así, un elemento diferenciador de la libre voluntad que, en este caso, tipifica la forma más clara de engaño.

En este sentido, se ha de valorar que la nueva forma de esclavitud que está asumiendo la fenomenología de la trata de seres humanos, requiere un nuevo planteamiento en materia de control y garantías sobre los derechos humanos que deben asistir, con carácter universal, a todas las personas con independencia del lugar en el que se encuentren. En este sentido, resulta destacable como la trata de seres humanos se presenta como un fenómeno transnacional que se proyecta a nivel mundial. Y por todo ello, resulta de extrema necesidad que se articule medidas consecuentes con este nuevo fenómeno mundial que conlleven entre otras, las mayores garantías para los derechos inherentes al ser humano.

\footnotetext{
${ }^{39}$ Ibídem, p. 63.
} 


\section{REFERENCIAS BIBLIOGRÁFICAS}

ARA PINILLA, I., Las transformaciones de los derechos humanos, Tecnos, Madrid, 1994.

BALES, K., La nueva esclavitud en la economía global (traducción de Borrajo Castanedo), Siglo XXI Editores, Madrid, 2000.

FERNÁNDEZ OLALLA, P., "Una aproximación práctica a la lucha contra la trata de seres humanos en España", en AA.VV., M. C. Vidal Fueyo (coord.) La Trata de Seres Humanos, Centro de Estudios Políticos y Constitucionales, Madrid, 2012.

FERNÁNDEZ-ARMESTO, F., Breve historia de la humanidad, Ediciones B, Barcelona, 2005.

FERRAJOLI, L., Sobre los derechos fundamentales, Trotta, Madrid, 2001.

FINLEY, M. I., Esclavitud antigua e ideología moderna, Barcelona, Crítica, 1982.

GALVÁN TELLO, M. C., "La educación en Derechos Humanos en la enseñanza del Derecho: un desafío", en Los derechos humanos en la educación jurídica, Plaza y Valdés, México, 2012.

GARCÍA VÁZQUEZ, S., "Inmigración ilegal y Trata de personas en la Unión Europea: La desprotección de las víctimas", en Revista de Derecho Constitucional europeo, Año 5, Número 10, julio-diciembre, 2008.

GARCÍA VÁZQUEZ, S., "La lucha contra la trata de seres humanos a nivel internacional, comunitario y nacional", en AA.VV., M. C. Vidal Fueyo (coord.) La Trata de Seres Humanos, Centro de Estudios Políticos y Constitucionales, Madrid, 2012.

MARINA, J.A. y VALGOMA, M., La lucha por la dignidad, Anagrama, Madrid, 2005.

MUÑOZ CONDE, F., Derecho Penal. Parte Especial, Tirant lo Blanch, Valencia, España, 2010, p. 356.

NICOLÁS LAZO, G., "Migraciones femeninas y trabajo sexual: Concepto de trabajo precario versus tráfico de mujeres", AA.VV., R. Bergalli (coord.) Flujos migratorios y su (des)control. Puntos de vista pluridisciplinarios, Anthropos, Barcelona, 2006.

OIM, Trata de Personas: Aspectos Básicos, Cim/Oea, México 2006, p. 9.

PASCUAL LAGUNAS, E., Configuración jurídica de la dignidad humana en la jurisprudencia del Tribunal Constitucional, Bosch, Barcelona, 2009.

PÉREZ ALONSO, E. J., "La Trata de seres humanos en el Derecho Penal Español", en AA.VV., C. Villacampa Estiarte (coord.) La Delincuencia Organizada: Un reto a la Política Criminal Actual, Aranzadi, Navarra, 2013.

PÉREZ ALONSO, E. J., Tráfico de personas e inmigración clandestina (un estudio sociológico, internacional y jurídico-penal), Tirant lo Blanch, Valencia, 2008. 
PÉREZ CEPEDA A. I., Globalización, tráfico internacional ilícito de personas y derecho penal, Comares, Granada, 2004.

PÉREZ LUÑO, A. E., Los Derechos Fundamentales, Tecnos, Madrid, 1984.

RAMONET, I., "Esclavos en Europa”, en Le Monde Diplomatique, Número 189, Valencia, 2011.

SÁNCHEZ GARCÍA DE PAZ, M. I., La criminalidad organizada: aspectos penales, procesales, administrativos y policiales, Dykinson, Madrid, 2009.

SERRA CRISTOBAL, R. y LLORIA GARCÍA, P., La trata sexual de mujeres. De la represión del delito a la tutela de la víctima, Ministerio de Justicia de España, Madrid, 2007.

TESSIER, K., The New Slave Trade: The International Crisis of Immigrant Smuggling, Volumen XIII, Indiana Journal of Global Legal Studies, Indiana, 1995.

TODOROV, T., Frente al límite, Siglo XXI editores, México, 1993.

TRUYOL Y SERRA, A., Los Derechos Humanos, Tecnos, Madrid, 2000, p. 11.

VILLACAMPA ESTIARTE, C., El delito de trata de seres humanos. Una incriminación dictada desde el derecho internacional. Aranzadi, Pamplona, 2011.

Trabalho recebido em 13 de junho de 2017

Aceito em 31 de outubro de 2021 